\title{
Health Inequality as the Consequence of Drinking and Smoking in Case of the Czech Republic
}

\author{
Beata Gavurova 1*, Miriama Tarhanicova ${ }^{2}$, Adam Kulhanek ${ }^{3}$, Roman Gabrhelik 4 \\ 1,3,4 Department of Addictology, First Faculty of Medicine, Charles University and General University Hospital \\ in Prague; beata.gavurova@lf1.cuni.cz; adam.kulhanek@lf1.cuni.cz; roman.gabrhelik@lf1.cuni.cz. \\ 2 Faculty of Mining, Ecology, Process Control and Geotechnologies, Technical University of Kosice; \\ miriama.tarhanicova@tuke.sk \\ * Correspondence: beata.gavurova@lf1.cuni.cz; Tel.: +421-944-420-654 (B.G.)
}

\begin{abstract}
Background: Drinking and smoking have economic consequences and are the main risk factors of mortality and morbidity. Disease-specific deaths attributable to using substances present the primary health indicator in this study. This analysis focuses on mortality in productive age, 15 to 64 years since those deaths are considered the highest economic burden. Method: In the analytical part, data from the Registry of deaths of the Czech Republic for 1994 to 2017 were used. The number of deaths attributable to smoking and drinking was calculated using attributable fractions, based on literature review. This research aimed to reveal the gender differences in deaths attributable to drinking and smoking, according to age, and the differences in deaths regarding smoking or drinking. Results: The mortality attributable to smoking and drinking differs across age groups and genders. The highest median share of tobacco-related deaths is in the age group, 60-64 years. The highest median share of alcoholic deaths is in the age group of 50-54 years. Conclusions: There are significant differences between genders in both, smoking and drinking. A prevention program should be targeted to different age groups.
\end{abstract}

Keywords: alcohol, tobacco, mortality, mortality as health indicator, health inequality

\section{Introduction}

Globally, drinking and smoking, belonging to the group of legal drugs, are phenomena representing the economic burden. WHO estimates that approximately 8 million people die each year due to smoking [1]. In general, smoking kills about half of the people who smoke. On the other hand, in 2016, alcohol killed more than 3 million people (5.3\% of all deaths). Those deaths rose into 132.6 million disability-adjusted life years (DALYs). The prevalence of heavy alcohol use and daily tobacco use is the highest in Europe. The age-standardized prevalence of alcohol dependence is estimated to be 843.2 per 100000 people. According to the newest research in 2017, the prevalence of tobacco deaths was 110.7 deaths per 100000 people., followed by alcohol deaths (33.0 deaths per 100000 people) [2]. Several studies have addressed the negative impact of alcohol consumption and smoking on human health and society [3-8].

To eliminate the prevalence of smoking and alcohol consumption, and to reduce the negative impacts of these substances, many countries create new intervention programs. Numerous regional, national, and international researches provide an essential platform for these programs. In research programs, there is a gap of building international research teams that examine appropriate usage of health indicators across the separate geographical areas, in more detail. Similarly, various global crises and risks, such as the present COVID-19 pandemics, represent a proof of an increasing significance of using appropriate health indicators to describe the actual state of health population. In most studies, there is highlighted need for more in-depth research of health indicators as the lack of data disables making appropriate comparison of health level across countries. 
Studies dealing with legal drugs' social impact on health and economy examine different alcohol or tobacco consumption levels. The economic aspect of drug-using is widely defined as a social cost. That cost represents health care expenditure, law enforcement, lost productivity, and other direct and indirect costs, including harm to others [1]. The interest in exploring these areas is growing with the expanding adverse effects of legal drug use. The so-called meta-analysis is used to quantify the relation between legal drugs and their consequences. Those studies take into account many diagnoses attributable to alcohol or cigarettes. Considering the ICD -10 , in many cases the attribution is known by definition. However, there are diagnoses related to substances only partially. Using only the underlying cause of death undoubtedly underestimates the burden of alcohol-related harm and may give an inaccurate picture of those most likely to suffer from alcohol-related deaths, especially among younger men [9]. The adverse effects of smoking and drinking include mortality and morbidity, that represent the lost productivity. From the economic point of view, the mortality and morbidity is essential mainly in productive part of population (from 16 to 64). To this fact, we considered the deaths in productive age of population. Using drugs diminishes the health status of the population, both mortality and morbidity are generally considered to be the significant indicators of health.

Many socioeconomic factors seem to be the starting point of smoking and drinking addiction. One of them is the place of living. According to authors Fukuda et al., living in urban areas negatively influences a raised probability of smoking [10]. The next factor is the education level and the age of people. According to authors Bilal et al., the smoking prevalence is lower in women with a higher level of education [11-12]. Women are the ones who seek alcoholic treatment earlier. To this fact, they have a higher probability of getting over the addiction compared to men [13]. Recent findings show the differences between genders within alcohol use disorders decreased over time. Male drinkers consume larger alcohol quantities than female drinkers do [14]. Not only the amount but also the frequency of drinking is higher in the case of men. Generally, women are consistently more likely than men to be life-time abstainers [15]. Marriage positively influences smoking at a younger age, even though its adverse effects in older people are expected. The country's income level might affect its citizens' smoking and drinking habits [10]. In high-income countries, older age is associated with more frequent drinking but smaller quantities. Middle-income countries showed less frequent drinking but more massive amounts [16]. Moreover, biological factors lead to women's vulnerability to alcohol, such as different needs and motivations for drinking [17]. Discrepancy in alcohol and tobacco use within genders might influence the total number of deaths related to these substances. To confirm this assumption, we studied gender differences comparing the share on deaths attributable to smoking and drinking in Czech Republic in productive age, separately for women and men. The given coherent facts motivated us also to perform this research separately for different age groups. The results are presented clearly in boxplots.

The understanding of drinking and smoking patterns influences policy-makers. Recommendations for policy-makers referencing alcohol consumption and potential health benefits should not be generalized to all ages [18]. To conclude our assumptions for this study, taking into account only deaths that occur in productive age of Czech population, there are differences between men and women in separate age groups; there are differences between deaths attributable to smoking and deaths attributable to drinking. The aim of this research is to study differences between deaths attributable to smoking and drinking and the differences in regard to the type of examined drug.

Study is divided into six chapters. First one brings the strong introduction to the examined issues. Following background of the study tells more about the previous studies done in the similar field of study. The materials and methods are concluded in the third part. The results are presented in the fourth chapter, followed by the discussion and conclusion.

\section{Background of the study}

Deaths attributable to smoking and drinking, as the health indicator, was the subject of the many previous studies. The authors were concentrated on many different aspects of mortality; its relation 
to other social factors; differences across regions and countries; differences within genders; predictions etc. Authors Pruckner et al. examined the predictions in alcohol-related deaths within the last four decades, in the WHO European Region [19]. The authors used data available from the WHO database. Their results suggest that from 1979 to 2015, the age-standardized death rates due to selected alcohol-related causes decreased significantly for both sexes in all examined countries. As the authors also claim, the regional differences have been persisting. The authors also assume that if this trend was maintained (according to their model's results), the rate of alcohol-related deaths would decrease until 2030.

The alcohol attributable mortality has been decreasing in the last decades. However, it is related to avoidable mortality representing significant health and social burden for a country. This study offers many implications for the policies' creators. Probst et al. were ambitious in researching different alcohol consumption impacts on health among individuals with a low/high socioeconomic status [20]. Authors confirm a relation between alcohol consumption and socioeconomic status, even though the process in general is complex. This arise from the fact that it is hard to obtain relevant data necessary for correct research of interactive effects between alcohol consumption and socioeconomic status. However, it is also inevitable to examine drinking habits besides alcohol consumption. Alcohol consumption and alcohol-attributable mortality remain a perspective strategy to eliminate inequalities in population health.

Similarly, it is necessary to examine complex relationships between risks related to alcohol consumption, socioeconomic status, and mortality to create relevant policies in population health. Collins examines the relationship between socioeconomic status and alcohol consumption [21]. The research findings suggest that people with higher socioeconomic status may consume the same or even higher amount of alcohol than people with a lower socioeconomic status. However, the latter group seems to bear a disproportionate burden of negative alcohol-related consequences. The author claims that research of associations among these variables is more complicated due to the influence of race, ethnicity, and sex. The group of people with a lower socioeconomic status also consists of various marginalized communities with race and ethnic minorities, homeless people, etc., who may experience more significant alcohol-related consequences. The study appeals to creation of multilevel interventions that would consider risks at an individual's level. These economic differences are caused by higher negative consequences of alcohol consumption in more marginalized and vulnerable populations. In the study, Stefler et al. deal with smoking and alcohol consumption impacts on cancer-related mortality [22]. The aim of their study was to calculate the population attributable risk fraction of cancer deaths from smoking and alcohol. The study focused on three countries: Russia, Belarus and Hungary. The authors examine these lifestyle factors' contributions to differences in male cancer mortality in each of these countries. Data were collected as a part of a retrospective cohort study. The study also declares that men in Eastern Europe have the highest mortality rate of cancer in the world. Similarly, in Eastern Europe, there is a high prevalence of smoking. According to the analysis results, in Eastern Europe, there may be at least a third of cancer deaths in men caused by smoking and alcohol consumption. These findings should be implemented into the creation of health policies that focus on the population lifestyle factors.

Östergren et al. examined the inequalities in health in the northern countries. They aimed to research the impacts of smoking and alcohol consumption on the differences in life expectancy [23]. The authors used data registers in Denmark, Finland, Norway, and Sweden. Their study was focused separately on men and women in the age of 25 - 79 years, during the period between 1995 and 2007. The study results show that $40-70 \%$ of life expectancy differences in the northern countries are related to smoking and alcohol. The differences were determined among these countries, as well. The contributions' magnitude was about 30\% in Norway, Sweden, Finnish women, and around 50\% among Finnish men and Denmark. In conclusion, the authors state that smoking and alcohol consumption significantly impact the differences in the northern countries and sexes' mortality.

Leung et al. examined alcohol consumption and relevant consequences in adolescents in 1968 in low and middle-income countries [24]. The study aimed to compare the risks according to sex across these countries. The research sample consisted of 271156 adolescents aged $13-17$ years. The study results show the sex differences in the prevalence of alcohol use and consequences among adolescents 
living in low and middle-income countries. The study concludes that there is a higher probability of alcohol consumption in men than in women in all of the examined countries. Five countries (excluding Europe) recorded greater odds of intoxication in males. In America, South-east Asia, and Western Pacific, there were determined greater odds of alcohol-related problems amongst males. In Indonesia, Myanmar, Cambodia, Tuvalu, Morocco, Senegal, Kiribati, and Thailand, there were determined the highest odds of alcohol use among males compared to females. The study confirms the following conclusions: among adolescents - males living in low and middle-income countries had, on average, twice higher odds of drinking alcohol and experiencing adverse consequences. The authors appeal to the creation of prevention programs that would prevent a higher prevalence of alcohol consumption in researched countries in the future, which is probably a consequence of improved gender equality and increasing welfare.

Janssen deals in the study with research on changes in smoking impacts on life expectancy in the European countries [25]. The author also focuses on time changes and differences across the European countries and regions. The analyses' results show that smoking-attributable mortality contributed, on average, three years (43.5\%) to the 7-year life expectancy difference between women and men in 2014. However, the highest increase was evident in 1995, at 5.2 out of 9.0 years. Consequently, a decrease in parallel with the average sex difference in life expectancy was evident. The author concludes that the tobacco epidemic in the European countries will reduce differences in life expectancy between the sexes.

Smith et al. focused on research the differences in smoking cessation between men and women [26]. The authors identified 214 sex/gender difference tests from 190 studies through Medline. The authors also claim, based on many studies' results, that women have more difficulties maintaining long-term abstinence than men. The analyses show that the differences in smoking cessation between men and women are influenced by bio-psycho-social variation in samples across place and time. The authors also emphasize a need for more research in this area to recognize other important causalities for the proper setting of efficient prevention programs.

Leventhal shows the unequal effects of public health interventions on decreasing smoking addiction [27]. The author also emphasizes the significance of the factors, such as ethnicity/race, socioeconomic position, physical/behavioral comorbidity, and others. The author also claims that it is inevitable to create multilevel transdisciplinary models that are required for a comprehensive understanding of sources of tobacco-related health disparities. It is recommended to include into researches a new platform, 'socio-pharmacology,' in order to examine these factors more effectively. This would enable a better understanding of socio-pharmacological mechanisms that impact tobaccorelated health disparities. Consequently, it may influence a setting of more qualitative interventions within public health that would decrease tobacco-related health disparities.

The given research studies represent a valuable platform for the creation of national and international benchmarks in this area. They also motivate to realize other research and national and international comparative studies, which are inevitable for the creators of relevant policies and experts in public health to set effective prevention programs and realize national and regional strategic health plans.

\section{Materials and Methods}

We used the data from the Registry of Deaths of the Czech Republic for the period from 1994 to 2017. Data were obtained from the Institute of Health Information and Statistics of the Czech Republic as a part of the project "Economic Quantification of social cost as the results of alcohol, tobacco, and illicit drug use" under the Government Council for Drug Policy Coordination of Czech Republic. We cleaned the gathered data and removed all the duplicities and errors.

To better understand our way of calculation, it is necessary to define what present the words "category" and "group". In this study, we used the "category" to define the four categories of deaths: alcoholic deaths of men, alcoholic deaths of women, smoking deaths of men, and smoking deaths of women. As we were interested only in the deaths that occur in productive age, the "group" defines ten age intervals as follows: $15-19,20-24,25-29,30-34,35-39,40-44,45-49,50-54,55-59$, 
60-64 years. As we did the analysis based on the data from 1994 to 2017, we created the matrices of deaths related to smoking and drinking for each "category x group" in every year.

After the definitions, we continue by describing our method. First of all, it was necessary to identify the deaths that corresponds to each matrix. To make it easier to understand, we had to identify which of deaths from the Registry of deaths is related to smoking or drinking. Since this database contains the main cause of death, we picked diagnoses according to this criterion. To identify the diagnoses related to drinking or smoking, we did the literature review [28-33]. According to the diagnoses definition of ICD - 10, several diagnoses are a direct consequence of drinking/smoking. Such diagnoses are referred, in the literature, as $100 \%$ attributable to alcohol or tobacco use. To this, if someone died because of diagnose $100 \%$-related to alcohol, we will count this death as 1 . So, we will add 1 death to the total number of deaths related to alcohol.

For the other diagnoses, partly attributable to legal drugs, the attributable fractions were found in the literature. If someone died because of tobacco-partially-related diagnose, we add this death to the total number of deaths related to tobacco as corresponding fraction. To be exact, that means that only part of this death is related to smoking; this death occurred also because of the other factors. All the fractions are released in the final report of the project [34].

Next, we standardized the number of deaths per 100000 for each category $x$ group. The agestandardization method presented by West and Kanchanaranksa and Naing was implemented [3536]. As the reference population, we used the World Standard Population defined by WHO [37]. The corresponding results are shown in chapter 4.1 and chapter 4.2

Then we divided the number of deaths corresponding to each category $\mathrm{x}$ group by total number of deaths corresponding to each group, so in the four group, we calculate the share on death in age interval on total number of deaths attributable to drinking/smoking. This number represent the indicator of health in this study. To better understand the differences between genders and age group we then created the boxplots and compare the median value of those shares.

\section{Results}

In the first subchapter, the standardized number of deaths attributable to drinking and smoking is calculated. Generally, quantification of the effects of drug use includes calculation of the so-called lost productivity. This lost productivity represents the number of years lost or the productivity lost due to premature death. Lost years refer to the potential number of years that a person could reach if he or she did not die due to drug use [32], [38-39]. It is, therefore, important whether the person who died was at a productive age or not. The calculations are made concerning the population's age and sex, while the analysis is focused on people of working age (from 15 to 64 years).

The following subchapters show the differences within share on death attributable to smoking and drinking separately for different age groups and genders. Since we want to know, whether the mortality attributable to smoking/drinking is higher in case of younger or older people, we created the boxplots. The boxplots help to determine the median value, the Q1 (1. quartile)/ Q3 (3. quartile) of share on deaths corresponding to smoking and drinking in age interval. The subchapter 4.2 informs about the median values of share on deaths attributable to smoking/drinking in case of men. Following subchapter, 4.3 brings the results (median values), of share on deaths attributable to smoking/drinking in case of women.

\subsection{Number of deaths attributable to drinking and smoking}

Figure 1. shows the calculated number of deaths attributable to drinking and smoking in the case of the Czech population from 1994 to 2017. As seen, from 1994 to 2017, there is a decrease in the standardized number of deaths resulting from drinking and smoking. The decline is recorded for both men and women. Although an almost linear decrease in the number of deaths is evident in alcohol, this is not the case in smoking (we see a relatively turbulent development in the number of standardized deaths per 100 thousand). As can be seen, the number of deaths due to smoking is higher than deaths associated with alcohol use. 


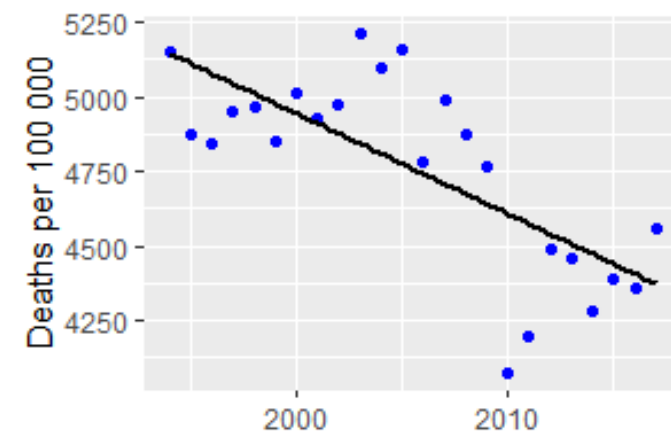

(a)

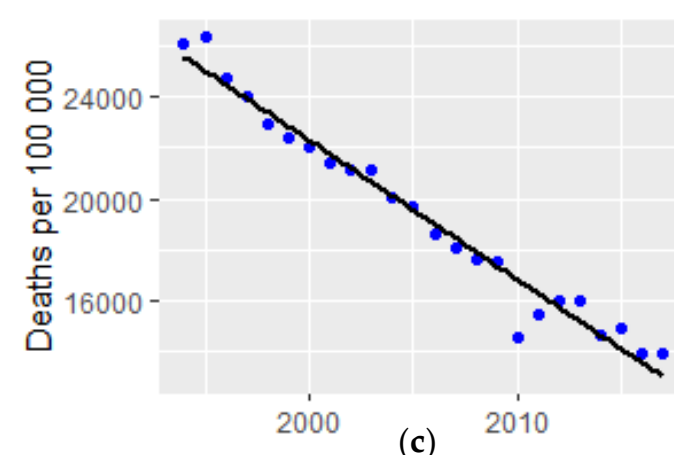

(c)
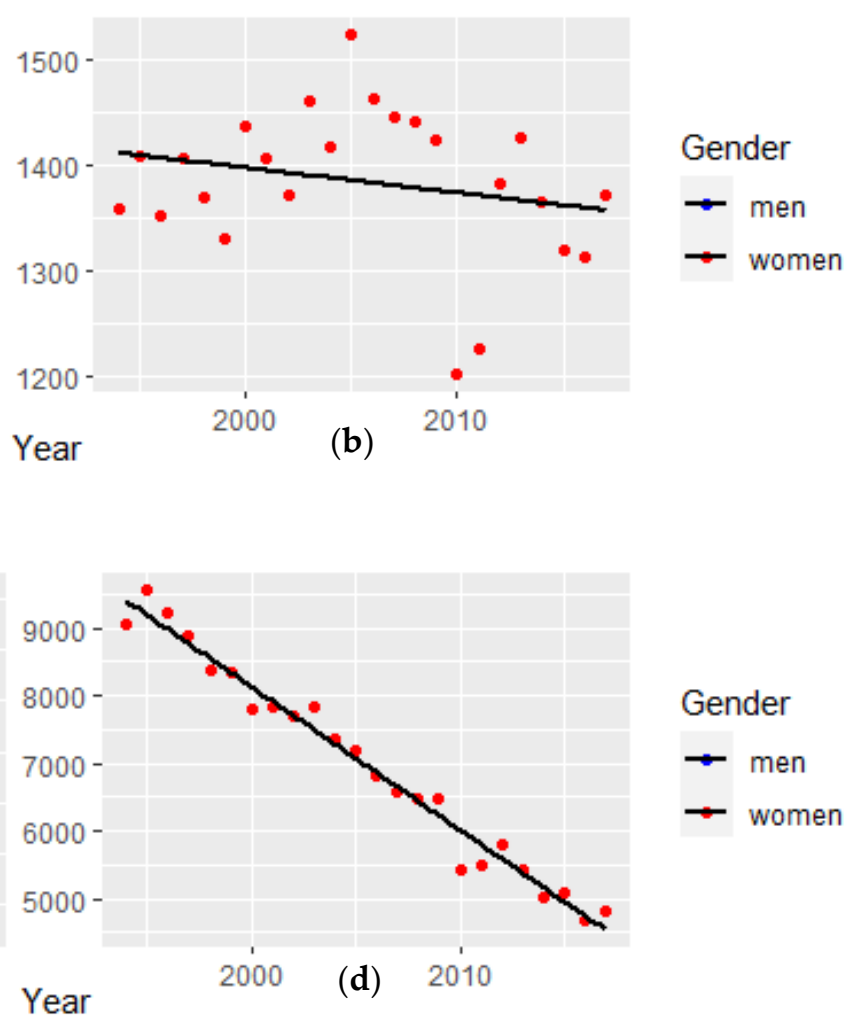

Figure 1. A standardized number of deaths attributable to drinking and smoking in the Czech Republic from 1994 to 2017. a) The number of men deaths attributable to drinking; b) The number of women deaths attributable to drinking; c) The number of men deaths attributable to smoking; d) The number of women deaths attributable to smoking.

The differences in standardized number of deaths are seen even among sexes. The standardized deaths attributable to alcohol is almost three times higher in men than in women. In case of smoking, number of standardized deaths is also almost three times higher in men than in women. According to standardized number of deaths, we know there exist differences among genders.

\subsection{The Share on Men Deaths Attributable to Smoking and Drinking in Productive Age}

As Figure 2 shows, in case of deaths of men aged 15 to 34 (young adult), the median value of share of deaths on the total number of deaths attributable to drinking in the productive population is between 1,9-4,8\%. The highest median value corresponds to deaths occurs in the age from 30 to 34 years. The lowest median value is known in the age group 15 do 19 years. The median value of share on deaths, in case of smoking is lower than in case of alcohol. For the same age interval (15 to 19 years), the median value of share on deaths corresponds to $0,18-0,4 \%$. The lowest median value is in age group of 15 to $19(0,18 \%)$, however, there is an outlier value of $0,25 \%$. On the other hand, the highest median value corresponds to age interval 25-29 years, with value of $0,4 \%$. Although, it might be seen, that in case of age interval $29-34$, there is an outlier value of $1,05 \%$ that exceeds mentioned median value.

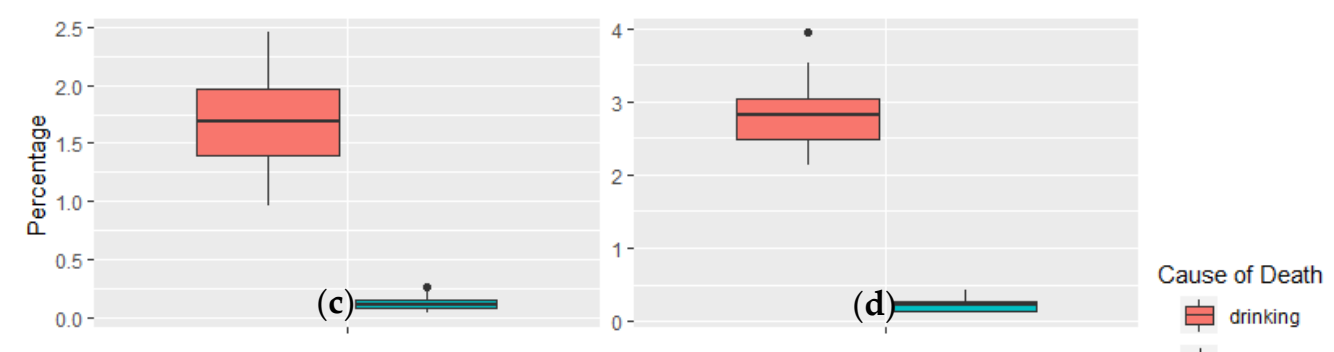


(a)

(c) (b)

(d)

Figure 2. Boxplots of men deaths attributable to drinking and smoking corresponding to different age groups on total deaths attributable to drinking and smoking men in productive age. a) Deaths share of men at the age of $15-19$ years; b) Deaths of men at the age of 20 - 24 years; c) Deaths of men aged $25-29$. d) Deaths of men aged $30-34$ years.

Based on the results presented in Figure 3, it can be said that even in the case of middle-aged men (from 35 to 49 years), a higher median value of deaths share was attributable to drinking (compared to smoking). The median of share on deaths attributable to smoking is almost five times lover compared to "drinking" median. The medians of deaths shares are higher in the case of middleaged than the medians of deaths share in case of young adults. However, the highest median value of share on deaths related to drinking/smoking was in case of 45-49 years old men. This median corresponds to $15,1 \%$. On the other hand, the lowest median, in age $35-39$, represents only $6,2 \%$. The highest median value related to smoking deaths of men represents about $8 \%$, and on the contrary, the lowest value is $1,2 \%$.

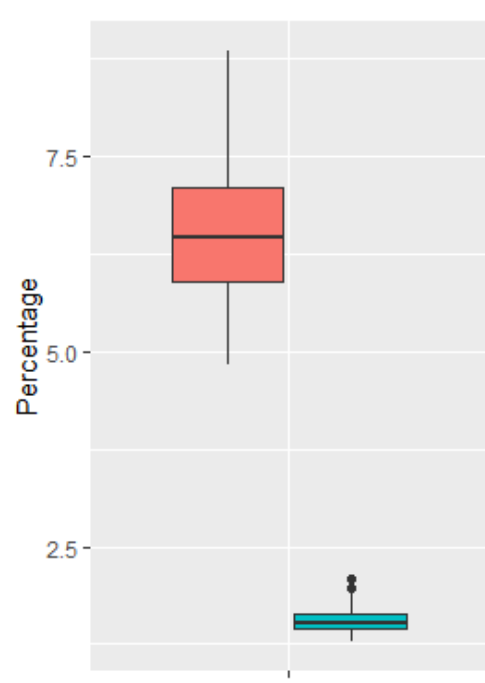

(a)

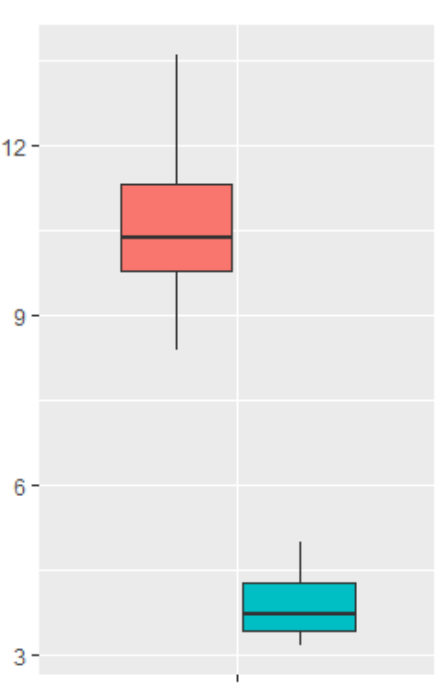

(b)

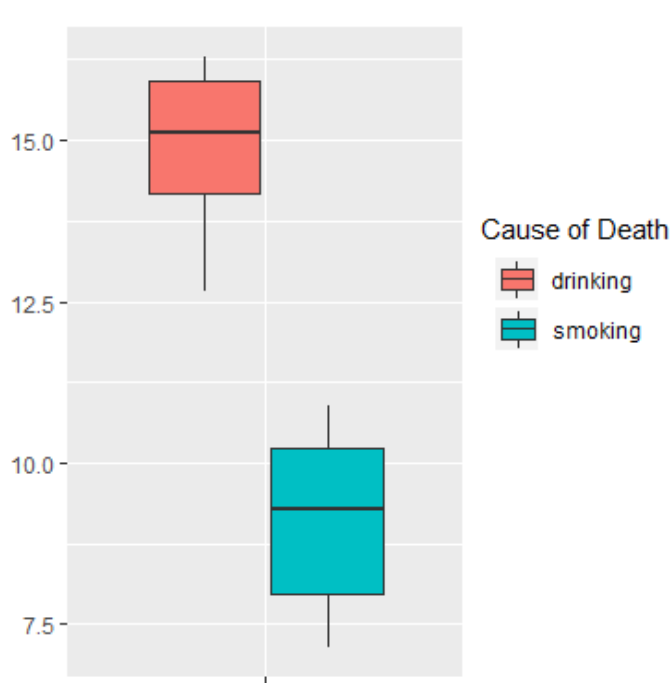

(c)

Figure 3. Boxplots of men deaths attributable to drinking and smoking corresponding to different age groups on total deaths attributable to drinking and smoking men in productive age. a) Deaths share of men at the age of $35-39$ years; b) Deaths of men at the age of $40-44$ years; c) Deaths of men at $45-49$ years. 
Figure 4 represents the share of men's deaths in productive age attributable to drinking and smoking for age groups 50-54, 55-59, and 60-64 years. As might be seen on previous figures ( 3 and 4) in the age intervals from 15 to 49 years, there was a significant difference between median value of share on deaths caused by smoking and drinking. Median deaths share caused by drinking was higher. However, in case of men aged 55 to 64 years, the median of deaths related to smoking is higher than median of deaths related do drinking.

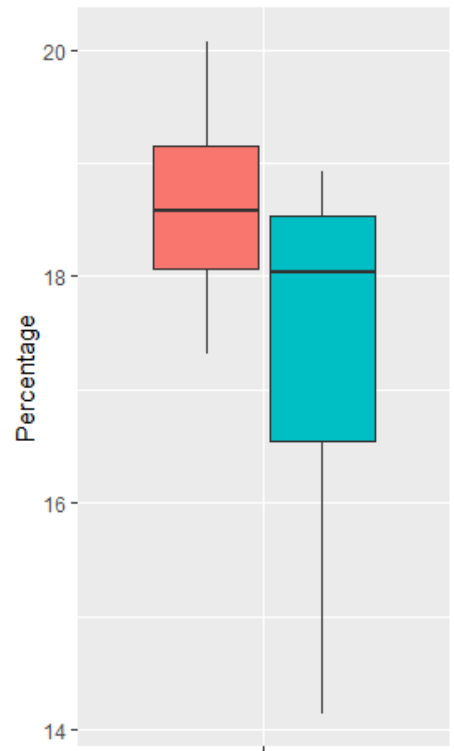

(a)

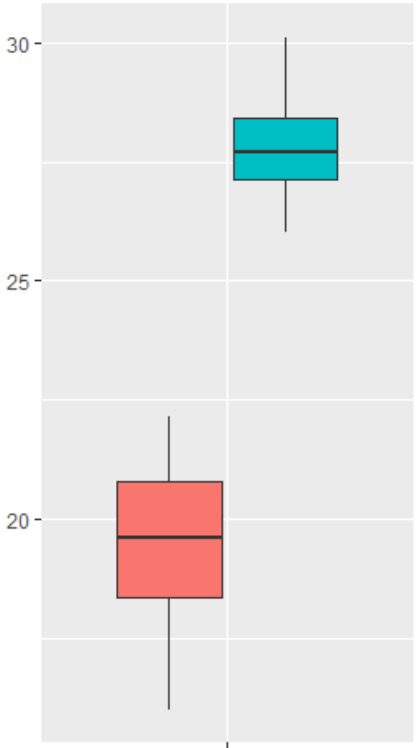

(b)

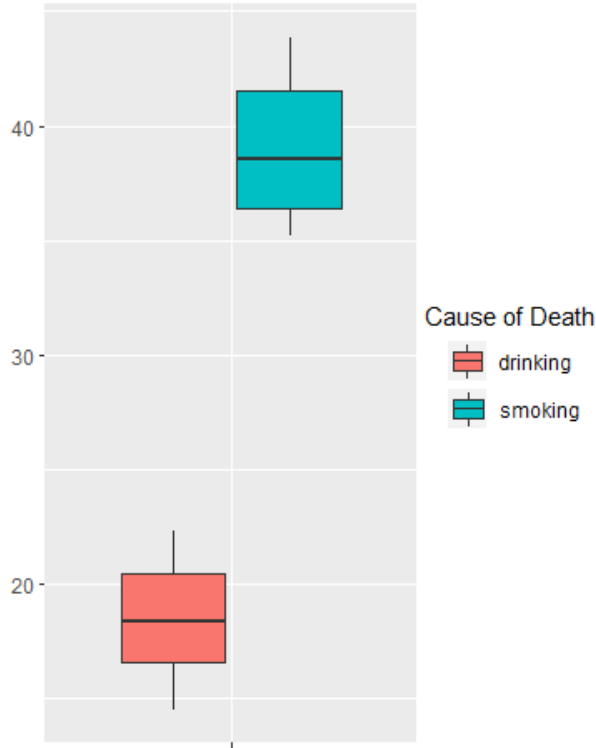

(c)

Figure 4. Boxplots of men deaths attributable to drinking and smoking corresponding to different age groups on total deaths attributable to drinking and smoking men in productive age. a) Deaths share of men at the age of $45-49$ years; b) Deaths of men at the age of $50-54$ years; c) Deaths of men at 55 -64 years.

While the median value of share on deaths attributable to drinking, in case of $45-49$ years old men, is around $18,5 \%$, the median value of share on deaths attributable to smoking is lower (about $18 \%$ ). The variance of both mentioned median value seems to be high, as Figure 4 also shows. Even there is a significant change in median value comparing the schemes a) and b) on Figure 4, the median value of share on deaths attributable to drinking in b) is higher then in a) with corresponding median value of $18,5 \%$ and $19,8 \%$. The slight decrease in "drinking" median is seen in c), with corresponding median value of $19,7 \%$. In case of smoking, the median value of share on deaths in c) represents almost $40 \%$.

\subsection{The share on women deaths attributable to smoking and drinking in productive age}

Since the effects of alcohol on women's mortality might differ from the mortality of men, the women share on deaths in productive age is part of this subchapter. As it might be seen in Figure 5, there is a difference between the median value of share on deaths in smoking and drinking. However, the median share of deaths attributable to drinking is higher. For women aged 15 to 19, the median share on deaths is slightly below $1,75 \%$. This median share of deaths increases when comparing next year intervals. To be exact, in b) the median share of deaths is nearly below $3 \%$; but outlier below $4 \%$ presented, in c) the median share on deaths is also below 3\% but in case of d) the median share on deaths attributable to drinking is above the $4 \%$. The variance of percentage is the highest in d) also. On the other hand, in case of smoking, the median value of share on deaths in case of women aged 15 to 19 is below $0,5 \%$. In $b$ ) the median of share on deaths is about $0,5 \%$. In the following age interval (from 25 to 29 years) the median share is slightly below $1 \%$. The age interval 30 to 34 years is known for the median share of about $1,5 \%$. 


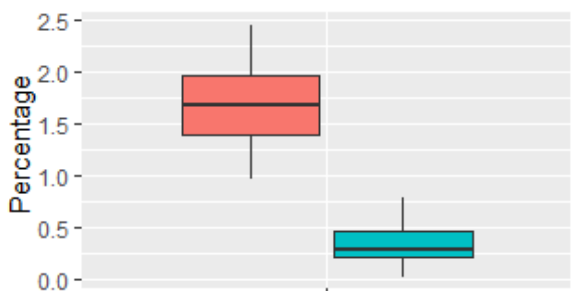

(a)

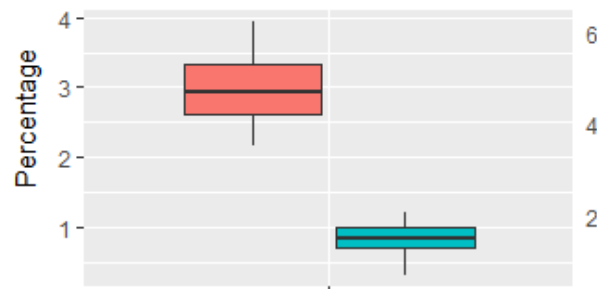

(c)

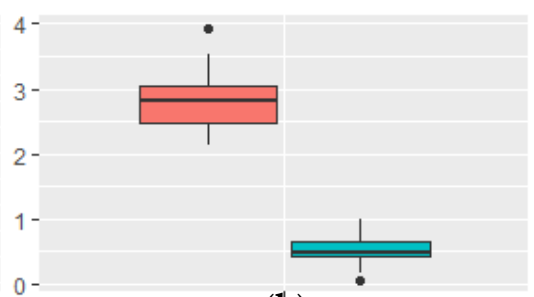

(b)

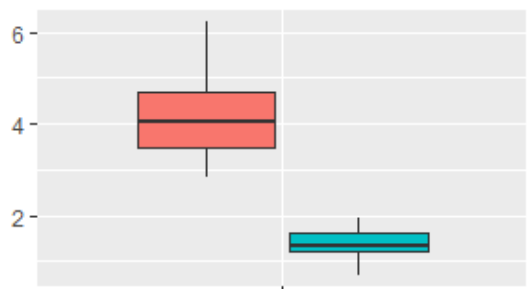

(d)
Cause of Death

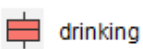

smoking

Figure 5. Boxplots of women deaths share attributable to drinking and smoking corresponding to different age groups on total deaths attributable to drinking and smoking women in productive age. a) Deaths share of women at the age of 15-19 years; b) Deaths of women at the age of 20-24 years;

c) Deaths of women aged 25-29 years. d) Deaths of women aged 30-34 years.

Share on deaths of women in productive age were higher in the case of alcohol. As seen in Figure 6 , the median share of alcoholic deaths in the age group 35 to 39 was nearly $7 \%$. The median of percentage of deaths attributable to smoking was above $3 \%$. In the case of women who died at $40-$ 44 years, there are higher discrepancies between smoking and drinking. While drinking median share on deaths in this interval is attributable close to $12 \%$, smoking is only attributable to nearly $6 \%$. The last chart in Figure 6 shows the share of deaths between $45-49$ years. As it is evident, drinking was attributable to nearly $17 \%$ of those deaths, while drinking was only below $10 \%$.

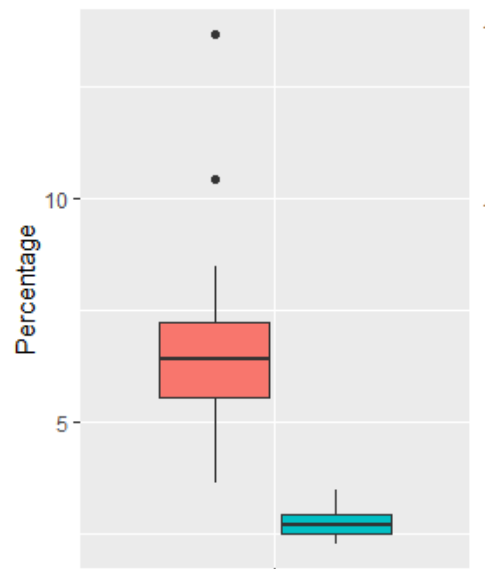

(a)

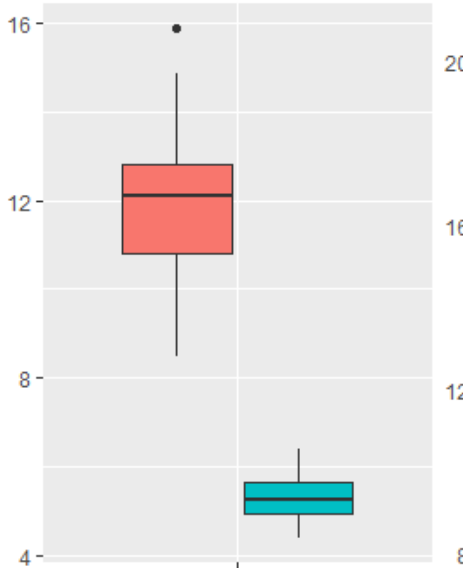

(b)

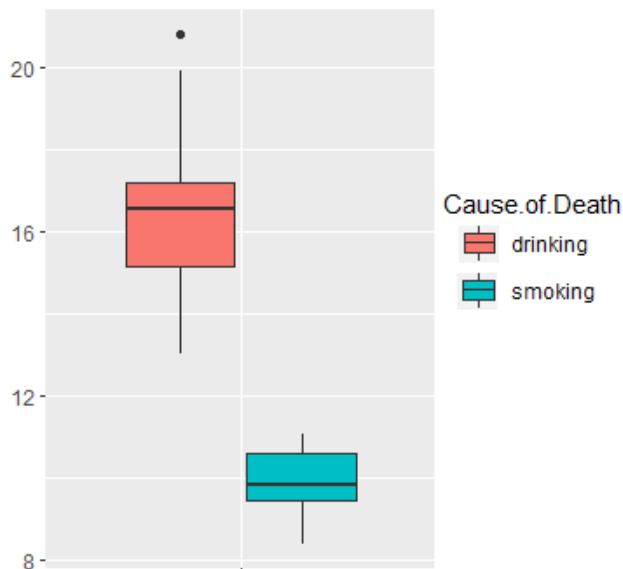

(c)

Figure 6. Boxplots of women deaths share attributable to drinking and smoking corresponding to different age groups on total deaths attributable to drinking and smoking women in productive age. a) Deaths share of women at the age of 35-39 years; b) Deaths of women at the age of 40-44 years; c) Deaths of women aged $45-49$ years.

Figure 7 shows the differences within medians of share on deaths of women caused by alcohol and tobacco in the age interval of 50-64 years from 1994 to 2017. For women aged 50 to 54 years, the median share of deaths because of drinking was higher compared to smoking. As a contrast, in case of women aged 55 to 64 years, median share on deaths attributable to smoking is higher than the median share of deaths attributable to drinking. This brings significant change in the trend of 
mortality caused by harmful effects of smoking and drinking. In the age group from 50 to 54 years, the median value of share on deaths attributable to drinking in case of women was below $18,5 \%$. However, the variance of shares is seen in Figure 7, in scheme a). There is an outlier median value of share below the $14 \%$. On the contrary, the median value of share on deaths attributable to drinking in case of 55-59 years old women, is above $20 \%$. In the age group 60 to 64 years, the median value of share on deaths attributable to drinking is even below $19 \%$. However, median value of share on deaths attributable to smoking is in b) below $26 \%$ and in c) is above $36 \%$.

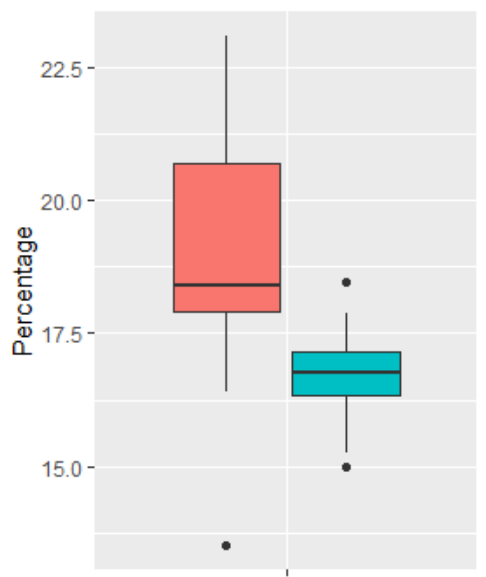

(a)

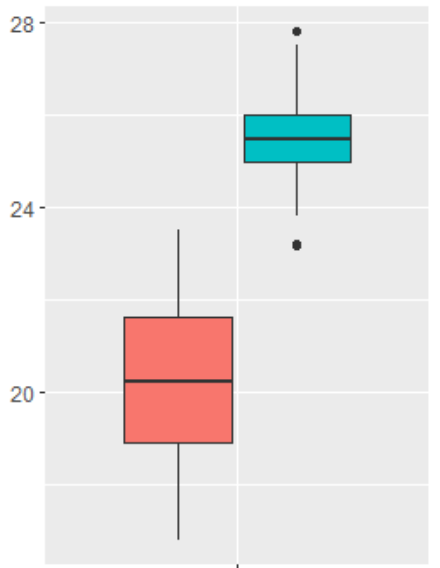

(b)

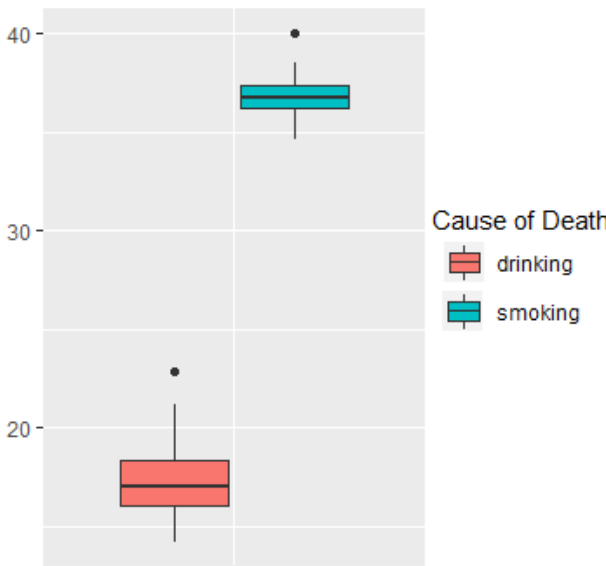

(c)

Figure 7. Boxplots of women deaths share attributable to drinking and smoking corresponding to different age groups on total deaths attributable to drinking and smoking women in productive age. a) Deaths share of women at the age of 50-54 years; b) Deaths of women at 55-59 years; c) Deaths of women aged $60-64$ years.

\section{Discussion}

According to the results, there is a downturn in standardized mortality attributable to smoking and drinking during the examined period. We can therefore say that the mortality trend in the Czech Republic reflects the global trend in alcohol consumption, that was also presented by Pruckner et al., [19]. Considering the standardized mortality as the health indicator, we might say, that during the examined period, the health of citizens has increased. While comparing mortality attributable to drinking or smoking, higher mortality is calculated in the case of tobacco. To this fact, smoking brings more negative effects, and diminish the health more drastically (compared to drinking).

In the Czech Republic, the number of deaths is higher in the case of men. However, the decrease in mortality in women's patients is lower than in the case of men. This might be the consequence of the fact mentioned in [13] that women are the ones who seek healthcare more than men. As shows study of Östergren et al., the alcohol and smoking negatively influence the life expectancy [23]. We can assume that the alcohol and tobacco reduce the health of people, and so consumption of both legal drugs bring the negative effect of amenable mortality and raising the number of lost years.

From 1994 to 2017, the proportions of deaths reached higher values in the older population's productive part. When comparing mortality due to drinking and smoking, alcohol consumption is significantly more dangerous for the economically productive population. Alcohol consumption has been associated with a higher median proportion of deaths in the lower age groups. In practice, that means that drinking alcohol brings a higher potential loss of productive life. However, the number of people who die as the result of smoking is more than twice higher comparing to number of people who die because of drinking, each year; all in all, those deaths may arise in society's same total loss because of alcohol compared to tobacco.

For both genders, we might conclude that the median share of deaths occurred in age of 15-34 years is up to $4 \%$. The median share of deaths of people aged $35-49$ is up to $17 \%$. In the case of the oldest productively active population, the median proportions of deaths represent up to $20 \%$; in the 
highest age intervals (from 55 to 64 years), it is even more than $20 \%$, up to $40 \%$. To this fact, the share on deaths as the indicator of health signifies, that the most significant negative health effect of smoking or drinking is in the oldest productively active population.

The median share on mortality related to smoking in the age group 15-34 is approximately the same for both men and women and is the lowest comparing to the following age groups. The age group, that includes middle aged people, i.e., from 35 to 49 years, was accompanied by a higher median share value of deaths due to alcohol consumption in the observed period in women's cases. This might be contradictory to [14], who says that men drink more and more frequently than women. However, it may also be because alcohol's effects are more negative for women than for men. Alcohol consumption of women is very specific and a woman's body responds to alcohol in a different way than man's body. These differences are especially related to anatomic, physiological and also psychological differences in both sexes. Smoking attributable mortality at this age is associated with the similar median share of deaths for both men and women, however according to our results we might say, that median share of smoking attributable deaths in age group 35 to 49 years is higher in case of women.

In the age group from 50 to 54 years the higher median proportion of deaths is attributable to alcohol use compared to smoking. During the observed period, 55 to 64 years' age is characterized by a higher median proportion of deaths associated with smoking, both in women and men. However, we observed higher differences in the proportions of alcohol and tobacco deaths for men for these age groups. Median share on deaths attributable to alcohol is higher in case of women (20,2 compared to median value of share of deaths of men, about 19,6\%). In the age group from 60 to 64 years, the share on deaths of women attributable to alcohol is about $18,5 \%$ and in case of men it is a $19,5 \%$. On the contrary the median percentage of women's deaths attributable to smoking in age group 55 to 59 is about $25,1 \%$ (median value for men is $27,5 \%$ ). In the last age interval, from 60 to 64 years, the median share on deaths attributable to smoking in case of women is $37,5 \%$ and $38,7 \%$ in case of men.

Alcohol consumption is the cause of several types of diseases. These diseases also include chronically non-communicable diseases representing a high economic burden for the health care system, health insurance companies, etc. Drinking alcohol at a younger age can deteriorate social status and lead to a person's degradation. Alcohol is often the cause of divorce or crime (primary but also a secondary crime). The territory of the Czech Republic is different in terms of its economic development and stability. These differences may be due to the level of drinking or smoking consumption and subsequent mortality. However, differences can also be the cause of people's educational level, social status, and thus, more determine alcohol consumption.

As alcohol mortality is attributable to lower age categories, it is necessary to focus on the younger population regarding prevention. Such preventive measures include, e.g., regulation of alcohol and cigarette marketing or raising the taxes. On the contrary, it is essential to focus on marketing the adverse effects. For companies that distribute tobacco or tobacco products, it is necessary to focus on developing and producing safer products that do not have negative impacts or their negative impacts are smaller than conventional tobacco products. Implementing new active control mechanisms to the market of addictive substances is also very important [40].

Similarly, prevention programs represent a useful tool that may eliminate the population's addiction to addictive substances. However, it is necessary to monitor and evaluate its efficiency regularly. There have been pressure on developing prevention programs that focus on various groups of a population in recent years, whether from a perspective of age differentiation or socioeconomic status, regional aspects, and others. The availability of health and social care for individuals with addiction is also a significant parameter as both treatment and prevention play essential roles. Late treatment effects or late determination of addiction may have fatal impacts on an individual and society. Prevention programs for the young population are particularly crucial as globalization, informatization, and also the influence of various harmful effects on their lifestyles influence their behaviour.

On the other hand, it is essential to focus on prevention experts who are supposed to be specialists in their field, and their knowledge and experience should reflect actual trends and prevention progress. In some countries, the development of training programs that ensure the 
development of a prevention workforce is also supported [41]. Also, the E-learning programs to Evaluate Online Training Courses in Prevention are developing [42]. For instance, the COVID-19 pandemics - which has a global dimension and strongly negative impacts on different aspects of society life - also influences the creation of specific prevention programs in the field of addiction in the individual countries. The global trends and a development of addictions in the individual countries presented in many domestic and foreign research studies put pressure on creating many multilevel intervention programs. These programs eliminate addictions and decrease health inequalities from the point of geography, age and gender differentiation [22], [43].

To compare smoking and drinking's economic impact in the Czech Republic, it is necessary to estimate the potential lost productivity in potential years of life lost. A more detailed analysis of lost years and comparisons of alcohol and tobacco use's final effects is needed and might be considered in future studies.

\section{Conclusions}

As the provided analysis show, there is a decline in standardized mortality attributable to smoking and drinking in the Czech Republic. During the period analysed, from 1994 to 2017, the number of deaths is higher in men. Mortality as the consequence of drinking and smoking brings economic damages. There is a necessity to get a new health policy involved in targeted prevention. As the study results show in the case of alcohol, the mortality is connected to younger ages. In terms of prevention of alcohol drinking, it is necessary to focus on the younger population. Women are more affected by alcohol consequences at a younger age. On the contrary, in the case of smoking, the median share on deaths attributable to smoking is higher in the older population.

Smoking and drinking attributable mortality in the Czech Republic reflects the global trend of declining use of these addictive substances. Deaths due to alcohol and tobacco use are dangerous, especially for people at working age. Such mortality has far-reaching economic consequences and causes significant damage to the health system and the social system. It is essential to combat drug use and step up prevention measures. It is necessary to further address this issue in cost studies and analyse this issue in the Czech Republic's regions because these regions' level and maturity differ.

This study confirms the assumptions of differences between men and women in separate age groups and differences between deaths in regard to smoking and drinking. Since legal drugs exist and its consumption is present in majority of countries, in Czech Republic as well, there exist health inequality that are the consequences of legal drugs use. To provide further analysis of health inequalities future studies should be concentrated on social factors that influence the alcohol consumption and smoking.

Author Contributions: "Conceptualization, B.G., M.T. and R.G.; methodology, M.T. and B.G.; software, M.T.; validation, B.G., M.T.; formal analysis, M.T.; investigation, B.G. and M.T.; resources, A.K. and R.G.; data curation, M.T.; writing-original draft preparation, M.T. and B.G.; writing-review and editing, A.K. and R.G.; visualization, M.T.; supervision, B.G.; project administration, A.K.; funding acquisition, B.G. All authors have read and agreed to the published version of the manuscript.

\section{Funding:}

This work is supported by the Government Council for Drug Policy Coordination of the Czech Republic as a part of the research project A-86-19: Economic Quantification of Social Costs of the Use of Alcohol, Tobacco and Illicit Drugs in the Czech Republic.

Conflicts of Interest: “The authors declare no conflict of interest."

\section{References}

1. WHO. WHO Report on the Global Tobacco Epidemic. Luxembourg, 2019. Accessed: Mar. 16, 2020.

[Online]. Available: https://apps.who.int/iris/bitstream/handle/10665/326043/9789241516204-eng.pdf?ua=1. 
2. Peacock, A. et al. Global statistics on alcohol, tobacco and illicit drug use: 2017 status report. Addiction, vol. 113, no. 10. Blackwell Publishing Ltd, pp. 1905-1926, Oct. 01, 2018, doi: 10.1111/add.14234.

3. Devlin, N. J.; Scuffham, P. A.; Bunt, L. J. The social costs of alcohol abuse in New Zealand. Addiction 2019, 92(11), 1491-505, Nov. 1997, Accessed: Jan. 06, 2019. [Online]. Available: http://www.ncbi.nlm.nih.gov/pubmed/9519492.

4. Alberto Vella, V.; García-Altes, A.; Segura García, L.; Ibáñez Martínez, N.; Colom Farran, J. Systematic review of guidelines in estimating social costs on drugs. Gac. Sanit. 2018, 32(5), 481-487. doi: 10.1016/J.GACETA.2017.10.009.

5. Xie, X.; Rehm, J.; Single, E.; Robson, L.; Paul, J. The economic cost of alcohol abuse in Ontario. Pharmacol 1998, 37(3), 241-249. doi: 10.1006/PHRS.1998.0293.

6. Fenoglio, P.; Parel, V.; Kopp, P. The social cost of alcohol, tobacco and illicit drugs in France. Eur. Addict. Res. 2003, 9(1), 18-28. doi: 10.1159/000067730.

7. Gutjahr, E.; Gmel, G.; Rehm, J. Relation between Average Alcohol Consumption and Disease: An Overview. Eur. Addict. Res. 2001, 7(3), 117-127. doi: 10.1159/000050729.

8. Thavorncharoensap, M.; Teerawattananon, Y.; Yothasamut, J; Lertpitakpong, C.; Chaikledkaew, U. The economic impact of alcohol consumption: a systematic review. Subst. Abuse Treat. Prev. Policy, 2009, 4(1), p. 20. doi: 10.1186/1747-597X-4-20.

9. Durkin, A.; Connolly, S.; O’Reilly, D. Quantifying alcohol-related mortality: Should alcohol-related contributory causes of death be included? Alcohol Alcohol. 2010, 45(4), 374-378. doi: 10.1093/alcalc/agq025.

10. Fukuda, Y.; Nakamura, K.; Takano, T. Socioeconomic pattern of smoking in Japan: Income inequality and gender and age differences," Ann. Epidemiol. 2005, 15(5), 365-372. doi: 10.1016/j.annepidem.2004.09.003.

11. Bilal, U.; Beltrán, P.; Fernández, E.; Navas-Acien, A.; Bolumar, F.; Franco, M. Gender equality and smoking: A theory-driven approach to smoking gender differences in Spain. Tob. Control 2016, 25(3), 295300. doi: 10.1136/tobaccocontrol-2014-051892.

12. Denney, J. T.; Rogers, R. G.; Hummer, R. A.; Pampel, F. C. Education inequality in mortality: The age and gender specific mediating effects of cigarette smoking. Soc. Sci. Res. 2010, 39(4), 662-673. doi: 10.1016/j.ssresearch.2010.02.007.

13. Erol, A.; Karpyak, V. M. Sex and gender-related differences in alcohol use and its consequences: Contemporary knowledge and future research considerations. Drug and Alcohol Dependence, 2015, 156, 113. doi: 10.1016/j.drugalcdep.2015.08.023.

14. Wilsnack, R.W.; Wilsnack, S. C.; Kristjanson, A. F.; Vogeltanz-Holm, N. D.; Gmel, G. Gender and alcohol consumption: Patterns from the multinational GENACIS project. Addiction, 2009, 104(9), 1487-1500. doi: 10.1111/j.1360-0443.2009.02696.x.

15. Wilsnack, R. W. et al. Gender differences in alcohol consumption and adverse drinking consequences: Cross-cultural patterns. Addiction, 2000, 95(2), 251-265. doi: 10.1046/j.1360-0443.2000.95225112.x.

16. Chaiyasong, S. et al. Drinking patterns vary by gender, age and country-level income: Cross-country analysis of the International Alcohol Control Study. Drug Alcohol Rev. 2018, 37, S53-S62. doi: 10.1111/dar.12820.

17. Holmila, M.; Raitasalo, K. Gender differences in drinking: Why do they still exist? Addiction 2005, 100(12), 1763-1769. doi: 10.1111/j.1360-0443.2005.01249.x.

18. Arndt, V.; Rothenbacher, D.; Krauledat, R.; Daniel, U.; Brenner, H. Age, alcohol consumption, and allcause mortality. Ann. Epidemiol 2004, 14(10), 750-753. doi: 10.1016/j.annepidem.2004.01.004.

19. Pruckner, N.; Hinterbuchinger, B.; Fellinger, M.; König, D.; Waldhoer, T.; Lesch, O. M.; Gmeiner, A.; Vyssoki, S.; Vyssoki, B. Alcohol-Related Mortality in the WHO European Region: Sex-Specific Trends and 
Predictions. Alcohol and Alcoholism, 2019, 54(6), 593-598. doi: 10.1093/alcalc/agz063.

20. Probst, Ch., Kilian, C., Sanchez, S., Lange, S., Rehm, J. The role of alcohol use and drinking patterns in socioeconomic inequalities in mortality: a systematic review. The Lancet. Public Health 2020, 5(6), e324-e332. https://doi.org/10.1016/S2468-2667(20)30052-9

21. Collins, S. E. (2016). Associations Between Socioeconomic Factors and Alcohol Outcomes. Alcohol Res. 2016, 38(1): 83-94.

22. Stefler, D.; Azarova, A.; Irdam, D.; Scheiring, G.; Murphy, M.; McKee, M.; King, L.; Bobak, M. Smoking, alcohol and cancer mortality in Eastern European men: Findings from the PrivMort retrospective cohort study. International Journal of Cancer, 2018, 143(5), 1128-1133. https://doi.org/10.1002/ijc.31406

23. Östergren, O.; Martikainen, P.; Tarkiainen, L.; et al. Contribution of smoking and alcohol consumption to income differences in life expectancy: evidence using Danish, Finnish, Norwegian and Swedish register data. J Epidemiol Community Health, 2019, 73, 334-339.

24. Leung, J.; Chiu, V.; Connor, J.P.; Peacock, A.; Kelly, A. B.; Hall, W.; Chan, G. C. K. Alcohol consumption and consequences in adolescents in 68 low and middle-income countries - a multi-country comparison of risks by sex. Drug and Alcohol Dependence, 2019, 205, 107520.

https://doi.org/10.1016/j.drugalcdep.2019.06.022.

25. Janssen, F. Changing contribution of smoking to the sex differences in life expectancy in Europe, 19502014. European Journal of Epidemiology, 2020, 35, 835-841.

26. Smith, P. H.; Bessette, A. J.; Weinberger, A. H.; Sheffer, Ch. E.; McKee, S. A. Sex/gender differences in smoking cessation: A review. Preventive Medicine, 2016, 92, 135 - 140.

https://doi.org/10.1016/j.ypmed.2016.07.013

27. Leventhal, A. M. The Sociopharmacology of Tobacco Addiction: Implications for Understanding Health Disparities. Nicotine E Tobacco Research, 2016, 18(2), 110-121. https://doi.org/10.1093/ntr/ntv084

28. Webster, L.; Angus, C.; Holmes, J.; Brennan, A.; Gillespie, D. Alcohol attributable fractions for England. 2019.

29. Jones, L.; Bellis, M. A. Updating England-Specific Alcohol-Attributable Fractions. 2013. Accessed: Feb. 14, 2020. [Online]. Available: http://allcatsrgrey.org.uk/wp/download/public health/alcohol/24892ALCOHOL-FRACTIONS-REPORT-A4-singles-24.3.14.pdf.

30. Krueger, H.; Andres, E. N.; Koot, J. M.; Reilly, B. D. The economic burden of cancers attributable to tobacco smoking, excess weight, alcohol use, and physical inactivity in Canada. Curr. Oncol. 2016, 23(4), 241-249. doi: $10.3747 /$ co.23.2952.

31. Baliunas, D. et al. Smoking-attributable mortality and expected years of life lost in Canada 2002: Conclusions for prevention and policy. 2002. Accessed: Nov. 24, 2019. [Online]. Available: www.who.int/evidence.

32. Zabransky, T.; Belackova, V.; Stefunkova, M., Vopravil, J.; Langrova, M. Společenské náklady užívání alkoholu, tabáku a nelegálních drog v ČR v roce 2007, 1st ed. Praha: Centrum adiktologie PK 1.LF UK v Praze, 2011.

33. Patra, J.; Taylor, B., Rehm, J. T.; Baliunas, D.; Popova, S. Substance-attributable morbidity and mortality changes to Canada's epidemiological profile: Measurable differences over a ten-year period. Can. J. Public Heal. 2007, 98(3), 228-234. doi: 10.1007/BF03403718.

34. Project A-86-19: Economic Quantification of Social Costs of the Use of Alcohol, Tobacco and Illicit Drugs in the Czech Republic. Department of Addictology, First Faculty of Medicine, Charles University and General University Hospital in Prague.

35. Diener-West, M.; Kanchanaraksa, S. The Direct and Indirect Methods of Adjustment. 
http://ocw.jhsph.edu/courses/FundEpi/PDFs/Lecture7.pdf (accessed Aug. 19, 2020).

36. Naing, N. N. Easy way to learn standardization: direct and indirect methods. Malays. J. Med. Sci., 2020, 7(1), 10-5. Accessed: Aug. 19, 2020. [Online]. Available: http://www.ncbi.nlm.nih.gov/pubmed/22844209

37. Ahmad, O. B.; Boschi-Pinto, C.; Lopez Christopher, A. D.; Murray, J. L.; Lozano, R.; Inoue, M. Age Standardization of Rates: A Nwe Who Standard, 2001.

38. Degenhardt, L. et al. Global burden of disease attributable to illicit drug use and dependence: Findings from the Global Burden of Disease Study 2010. Lancet 2013, 382(9904), 1564-1574. doi: 10.1016/S01406736(13)61530-5.

39. Sepanlou, S. G. et al. The global, regional, and national burden of cirrhosis by cause in 195 countries and territories, 1990-2017: a systematic analysis for the Global Burden of Disease Study 2017. Lancet Gastroenterol. Hepatol. 2020, 5(3), 245-266. doi: 10.1016/S2468-1253(19)30349-8.

40. Petruželka, B.; Barták, M. Potential Indicators for the Analysis of the Association between Public Health and Drug Market Policing in the Czech Republic: Review of Public Health Indicators. Adiktologie 2019, 19(1-2), 135-143; doi 10.35198/01-2019-003-0001.

41. Henriques, S.; Broughton, N.; Teixeira, A.; Burkhart, G.; Miovský, M. Building a Framework Based on European Quality Standards for Prevention and E-learning to Evaluate Online Training Courses in Prevention. Adiktologie 2019, 19(3), 153-161. doi 10.35198/01-2019-003-0004.

42. Henriques, S.; Burkhart, G.; Miovský, M. The first University E-learning Study Programme Based on the Adaption of the EUPC: Portuguese Implementation Study. Adiktologie 2019, 19(1), 35-41. https://doi.org/10.35198/01-2019-001-0004

43. Collins, S. E. Associations Between Socioeconomic Factors and Alcohol Outcomes. Alcohol Res 2016; 38(1), $83-94$. 